\title{
Established industries as foundations for emerging technological innovation systems: The case of solar photovoltaics in Norway
}

\author{
Jens Hanson ${ }^{1}$ \\ ${ }^{1}$ Centre for Technology, Innovation and Culture, University of Oslo, P.O. Box 1108 \\ Blindern, 0317 Oslo, Norway: jens.hanson@,tik.uio.no
}

\begin{abstract}
Accepted version
Please cite the article as follows:

Hanson, J. (2017). Established industries as foundations for emerging technological innovation systems: The case of solar photovoltaics in Norway, Environmental Innovation and Societal Transitions, doi: https://doi.org/10.1016/j.eist.2017.06.001.
\end{abstract}

\begin{abstract}
This paper follows up on recent debates on relations between technological innovation systems (TISs) and context. Particular focus is placed on the role of established industries, which possess important resources for TIS formation. The paper contributes in two ways. First, the paper builds and expands upon the TIS framework to encompass beneficial relations between a TIS and its sectoral and technological context. Second, the framework is applied to the analysis of the emergence of a solar photovoltaic (PV) industry in Norway. The analysis first illustrates how an emerging TIS can benefit from an overlap with an established industry, which serves as a structural foundation and impacts key TIS processes. Second, the paper shows how relations between TIS and context change over time and range from supply chain interaction to more profound overlaps of system elements.
\end{abstract}

Keywords: technological innovation systems; context; industry formation; renewable energy; solar energy; resource flows 


\section{Introduction}

Established industries harbour much-needed resources for the development of new industries and technologies that are part of sustainability transitions. The transfer of resources would require a beneficial relation between established and emerging industries. While the relation between established and emerging industries has been at the heart of sustainability transitions research, much of this attention has been directed at instances characterised by conflict and antagonism (Geels, 2002). Positive relations and cases where established industries show higher degrees of adaptability to new technological opportunities have received less attention (Dolata, 2009). Both qualitative studies and suggestive theories that explain industry emergence and relations to factors prior in time have been called for (Forbes \& Kirsch, 2011; Krafft, Lechevalier, Quatraro, \& Storz, 2014). Recent contributions have opened to the inquiry of whether there is more to the relations between established and emerging industries than conflict (Berggren, Magnusson, \& Sushandoyo, 2015; Geels et al., 2016). The paper engages with this line of research with the purpose of analysing how processes of new industry formation can benefit from established industries and its associated actors and resources.

The paper applies the technological innovation system (TIS) framework, which has become a useful tool for analysing emerging industries (Markard, Raven, \& Truffer, 2012). Recent contributions call for conceptual strengthening and more empirical analyses of relations between TIS and context. This includes the context of established industries. In most studies, the context of a TIS is seen as a source of competition or suffering from lock-in, but in some cases, established industries can be beneficial for emerging industries (Frenken \& Boschma, 2007; Garud \& Karnøe, 2001). Arguably, strong relations to existing context structures could play a decisive role in new TIS formation (Bergek et al., 2015). Few studies focus explicitly on the conditions under which beneficial relations between mature industries and newly forming TISs emerge. We miss insights into how such relations are established and unfold. The paper contributes to the TIS field by analysing how such relations are created by exploring the following research question: how, and under which conditions, can an established industry contribute to TIS formation?

To explore this question, the paper extends the TIS framework and applies it to the analysis of the solar photovoltaic (PV) industry (PV-TIS) in Norway. The analysis focuses on how PV-TIS formation benefited from relations to the metallurgical silicon industry and the broader electrometallurgical industry sector. This case is useful for gaining insights into how established industries can play a beneficial role by acting as a structural foundation for new TIS formation, and affecting key TIS processes.

The following section introduces the analytical framework and methods employed in this article. Section 3 presents and analyses the case, while section 4 provides a discussion. Conclusions and suggestions for future research are provided in section 5 .

\section{Analytical framework}

\subsection{Relations between a Technological Innovation System and context}

A TIS consists of elements (actors, networks and institutions) that are engaged in generation, diffusion and utilisation of a specific technology (Bergek, Jacobsson, 
Carlsson, Lindmark, \& Rickne, 2008; Hekkert, Suurs, Negro, Kuhlmann, \& Smits, 2007; Markard \& Truffer, 2008). However, given its technology specific focus, the TIS approach has been criticised for being myopic with lacking attention to how TISs relate to their broader contexts (Markard \& Truffer, 2008). This critique has been met by Bergek et al. (2015) who suggest a scheme for TIS context analysis, based on how TISs relate to geographic, political, sectoral and technological contexts. This paper engages with this recent development and explores the circumstances under which these relations to context are established. Specifically, the paper explores the context of established industries, and how it can contribute to TIS formation processes.

\subsubsection{Specifying context}

As a starting point, the context must be specified. Established industries are here seen to provide context for the focal TIS along two dimensions - sectoral and technological. These contexts can overlap, but the paper distinguishes between them for analytical purposes to single out technology-specific resources from more general ones embedded in broader sectoral contexts.

Sectors are stable, institutionalised and regulated sociotechnical systems that follow particular technological trajectories and organisational patterns, in part depending on the technologies developed and used (Dolata, 2009). A sector thus can be seen as serving a particular function, such as the supply of energy or other products and goods, while multiple technologies are integrated with the sector to various degrees (Bergek et al., 2015). Sectors are built up of the same elements as a TIS noted above.

Previous studies have shown that established sectors can influence emerging TISs. Wirth and Markard (2011), for instance, show how the emerging biomass TIS in Switzerland depends on its connections with several sectoral contexts, both in terms of inputs (forestry and sawmill) and outputs (electricity and gas supply).

To discuss a beneficial sectoral impact on TIS formation, factors that enable the development of a positive relation between a sector and an emerging technology must be accounted for. Although much focus has been put on relations characterised by conflict and separation, emerging technologies and established sectors can also be tightly connected (Dolata, 2009). The main focus of this paper is on the creation of connections that involve the engagement of sectoral focal actors or transfer of resources from the sector. It has been empirically shown that new opportunities presented by emerging technologies can trigger actor entry from established sectors to newly forming TISs (Erlinghagen \& Markard, 2012; Wirth \& Markard, 2011). The exploration of these new opportunities can be triggered by changes in actors' selection environments. These include pressures and opportunities presented by new technologies (Dolata, 2009), firm-level pressures (i.e., pricing and competition) or broader pressures emanating from institutional change (Smith, Stirling, \& Berkhout, 2005).

Whether established sectors can connect with, and positively influence an emerging technology through actor entry or transfer of resources, depends on the sectors' institutionalised patterns of experimentation, openness and ability to interpret opportunities linked to new technologies. Furthermore, this openness and experimentation with emerging technologies not only depends on intra-organisational capabilities. Firms also rely on other firms, universities and research institutes to 
create an environment that is conducive to anticipation and interpretation of new technological opportunities (Dolata, 2009).

Since sectors are comprised of several technologies, and thus several TISs, we could expect that the opportunities to interpret and link up with emerging technologies would differ across the technological fields present in the sector (Bergek et al., 2015).

A proposition explored in this paper is whether search and experimentation in a technological field already integrated with an established sector helps to enable a relation that is beneficial for the focal TIS. This would entail the presence of a context TIS integrated with the sector, which has the potential to form a positive relation to the focal TIS. Much of TIS-TIS interaction occurs in supply chains, where one TIS supplies materials or technologies to another TIS (Bergek et al., 2015). Instances of more profound relations would entail overlap between the innovation system elements discussed in section 2.2.

This thus leads to specifying the technological context as the second context dimension provided by established industries. The paper thus distinguishes between two relevant contexts: the particular technological context (TIS) and the broader sectoral context to which these TISs relate. The inclusion of a technologically related context TIS provides the opportunity to analytically distinguish a particular technological context that enables a relation between the sector and focal TIS to materialise.

\subsubsection{Type of relation}

With regards to the potential types of relations between TIS and context, Sandén and Hillman (2011) develop a framework, which suggests that emerging technologies may enjoy a range of relations to established ones, ranging from pure conflict to pure symbiosis. The locus of interaction can be observed at the value-chain level, where two technologies may overlap in different forms at different levels of the value chain. Sandén and Hillman (2011) further suggest six patterns of relations, differentiated in terms of whether a technology has a positive, negative or neutral impact on the old technology and vice versa. All six dimensions are not explored here, but two key points remain relevant.

First, context may exert influence on the TIS along a spectrum ranging from positive to negative. For instance, a TIS may benefit from an established technology through access to resources and assets. Alternatively, the established technology could be competing over resources with the emerging TIS, and thus exert a negative influence (Bergek et al., 2015).

Second, relations between TIS and context range from being symmetric to asymmetric (Sandén \& Hillman, 2011). If an established technology positively impacts a TIS, it does not automatically imply a positive bidirectional relation. An established technology may impact an emerging technology positively, while the latter may have a negative or neutral impact on the established technology. TISs in formative phases can be expected to have limited impact on context (Markard, 2016).

\subsubsection{Flows from context to focal TIS}

Given the focus on how context influences TIS formation, the paper uses the notion of flows to denote transfer of knowledge, materials and other resources from the 
context(s) to the focal TIS. Flows have been shown to be important inputs to innovation (Acs, Audretsch, \& Feldman, 1994; Feldman, 1994; Smith, 2002). In particular, flows are important given how technologies evolve based on ' ... ancillary inventions or improvements, frequently from other industries...' (Mowery \& Rosenberg, 1998, p. 3).

The vehicles for transfer of resources are diverse and may be embodied (machinery, components, equipment, infrastructures, etc.) or disembodied (education, scientific literature, personnel, consultancy, etc.) (Smith, 2002). Absorptive capacity is important to enable such flows (Cohen \& Levinthal, 1990). Graf (2011) stresses the role of gate-keepers, the actors that enable the combination of local and external resource flows.

Flows thus represent the supporting role that an established industry might play through provision of resources, in addition to the role of shared elements discussed in the following section.

The notion of flows is supplementary to existing notions describing the relation between TIS and context (i.e., external links and structural couplings) (Bergek et al., 2015) and is applicable for cases where asymmetric relations that provide onedirectional impact are the primary focus.

\subsection{Shared elements}

Relations to contextual TIS and sectors are of importance as forming TISs can depend on shared elements for structural build-up (Bergek, Jacobsson, \& Sandén, 2008). In such instances, we can expect an overlap of system elements between TIS and context. The following section explores the role of shared elements for the structural build-up of a TIS, including actors, networks and institutions.

\subsubsection{Actors}

For a TIS to form, firms and other organisations must enter. Established industries may impact this positively through diversification, spin-offs and labour mobility (Frenken \& Boschma, 2007). First, in instances of related diversification, firms enter new industries due to technological relatedness (Breschi, Lissoni, \& Malerba, 2003; Neffke, Henning, \& Boschma, 2011). Diversifiers can bring with them core competencies to the TIS, as they have the advantage of employing competencies that have been used previously in the existing industry (Markides \& Williamson, 1994). Spin-offs are a second mode of actor entry, where previous employees of other firms engage with the new TIS by starting new firms. This is a second mode for transfer of key experiences and competencies from established and related industries. Spin-offs of incumbents generally perform stronger than other types of new firms (Klepper, 2002). Both types of actor entry provide opportunities for resource flows to materialise and thus to impact TIS functions such as knowledge development (Jacobsson, 2008). Finally, labour mobility is a third mode, which offers opportunities to transfer routines (Frenken \& Boschma, 2007).

\subsubsection{Networks}

Networks are an important building block in emerging TISs. Musiolik (2012) analyses the role of strategic deployment and development of network resources in 
early phase TIS formation. Based on the analysis of stationary fuel cells in Germany, Musiolik shows how system building and network formation was strategically aimed at addressing deficiencies in the technological field.

Networks may be both formal and informal and linked to learning (such as between firms or between industry and academia) or gaining political influence (Jacobsson, 2008). Overlap occurs when a set of actors linked to one technology at a later point engage with another technology (Sandén \& Hillman, 2011). The paper explores how networks established by context actors overlap with those of an emerging TIS.

\subsubsection{Institutions}

Institutions are seldom well aligned to an emerging TIS. Processes of TIS formation thus require the development of both formal (policies, regulations and standards) and informal (norms, visions and expectations) institutions (Jacobsson, 2008). Institutions thus guide the activities and interaction among actors in the TIS. The institutional setup of a context TIS and sector can be expected to influence emerging TISs in both constraining and enabling ways (Wirth \& Markard, 2011). Given the focus on overlaps, the paper mainly explores how institutional change in the context impacts the development of linkages to the emerging TIS.

\subsection{Key processes}

Finally, the paper draws on the TIS functional approach, here labelled as key processes (see Table 1 for the definitions) (Bergek, Jacobsson, Carlsson, et al., 2008; Hekkert et al., 2007). The functions approach was developed to analyse system dynamics, rather than just look at static structures. These key processes can be seen as underlying industry formation, and focus on what is achieved in a system. Bergek, Jacobsson, and Sandén (2008) argue that the functions approach is useful both in a 'performance diagnostic' sense, as well as to analyse dynamics evolving over time. As the paper focuses on how context influences TIS formation that occurs over time, the paper follows the latter approach to analyse how key processes were impacted upon by the context TIS and sector. The TIS functions approach has been used to account for both system specific as well as so-called exogenous structural elements that impact system dynamics (Markard (Markard, Hekkert, \& Jacobsson, 2015). Context structures thus also affect a TIS by influencing the development of its key processes. The paper applies the abbreviations in Table 1 (- indicates a negative impact).

\begin{tabular}{|l|l|l|}
\hline Process & Definition & Abbr. \\
\hline $\begin{array}{l}\text { Knowledge development } \\
\text { and diffusion }\end{array}$ & $\begin{array}{l}\text { Development and diffusion of knowledge in, and between, } \\
\text { firms and other actors. Includes differing forms of knowledge. }\end{array}$ & P1 \\
\hline $\begin{array}{l}\text { Entrepreneurial } \\
\text { experimentation }\end{array}$ & $\begin{array}{l}\text { Uncertain and risk-filled experimentation by new entrants or } \\
\text { diversifiers that introduce new knowledge and technology. }\end{array}$ & P2 \\
\hline Resource mobilisation & $\begin{array}{l}\text { Ability to mobilise financial and human capital as well as } \\
\text { infrastructures and complementary assets. }\end{array}$ & P3 \\
\hline $\begin{array}{l}\text { Influence on the direction of } \\
\text { search }\end{array}$ & $\begin{array}{l}\text { Incentive and pressure mechanisms that influence actor entry } \\
\text { to the TIS. }\end{array}$ & P4 \\
\hline Market formation & $\begin{array}{l}\text { Development of markets that often lack for novel technologies } \\
\text { at early stages. Entails development of early protective } \\
\text { learning markets and later development of mass markets. }\end{array}$ & P5 \\
\hline Legitimation & $\begin{array}{l}\text { Social acceptance and compliance with relevant institutions. } \\
\text { Legitimation processes lead to increased desirability. }\end{array}$ & P6 \\
\hline
\end{tabular}

Table 1: Key processes (based on (Bergek, Jacobsson, Carlsson, et al., 2008; Hekkert et al., 2007). 


\subsection{Analytical focus}

Figure 1 summarises and illustrates the analytical perspective outlined in the previous sections. It shows a focal TIS with overlaps to a context TIS and a broader sector through sharing of system elements. ${ }^{1}$ These contexts may also impact key processes evolving in the emerging TIS. Furthermore, Figure 1 depicts a focal TIS with a partial overlap to context to indicate that TISs may range from being fully integrated to not engaging much with the sector. Between these extremes, we may see differing types of connections depending on the extent of technology specific and shared elements (Bergek et al., 2015).

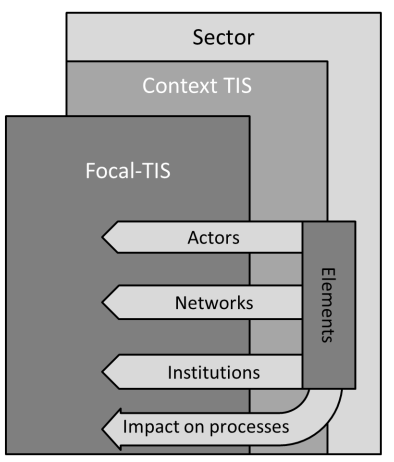

Figure 1: Analytical focus.

\subsection{Methods for data collection}

Given the purpose of analysing how an established industry contributes to TIS formation, the paper employs an explanatory case study strategy to arrive at analytical generalisations (Punch, 2005). Such an approach is favourable when specific attention to the case context is required. The framework proposed above is applied to analyse how a relation between TIS and context is established. Section 3.1 on system delineation describes how the key concepts relate to the empirical case and its contexts.

Data for the analysis were mainly obtained through eight in-depth interviews with key stakeholders in firms (CEO or technical management level), research organisations and public authorities. Informants were selected based on an initial evaluation of their role and position to secure that they had been active participants in key events already at early stages, or had in-depth knowledge of processes that lead to the formation of a PV industry in Norway. Informants were identified using snowball sampling in combination with reviewing newspaper articles using the Retriever online media database. Given the rather small number of actors linked to PV in Norway, particularly at the early stages, these respondents are seen to cover the main group of actors.

\footnotetext{
${ }^{1}$ It is beyond the scope of this paper to provide a full TIS analysis of the context TIS and sector, but rather to focus upon those parts of the context that have structural overlaps or have impacted the key processes of the focal TIS.
} 
The interviews are combined with data from secondary sources and documentary data (news articles and reports). These are used to depict the current and historical background of the focal TIS, context TIS and sector. Previous studies of the Norwegian PV industry, discussed in section 3.1.2, were also consulted to develop the case analysis. Finally, key informants reviewed and provided comments on earlier drafts.

\section{Analysis}

The paper applies the framework outlined in Section 2 to analyse the role of context during the formation of a PV-TIS in Norway.

\subsection{System delineation}

This section delineates the focal TIS and context.

\subsubsection{Focal TIS}

The Norwegian PV industry (focal TIS) has evolved since the mid-1990s (Hanson, Kasa, \& Wicken, 2011; Klitkou \& Godoe, 2013). Normann and Hanson (2015), based on a survey of Norwegian PV firms, identify about 60 firms and other actors with PV related activities, of which many have an international orientation. These include some large firms such as Elkem Solar, Norsun and Scatec Solar. However, most firms are small (about $65 \%$ with $1-4,25 \%$ with $5-25$, and $10 \%$ with above 25 full-time employees) (Normann \& Hanson, 2015). Firms are concentrated in the supply chain segments of raw materials, downstream system integration and research and development (R\&D) and consultancy (see Figure 2).

Domestic deployment levels have been marginal, with below $500 \mathrm{kWp}$ being installed annually. In 2014, deployment increased to 2.2 MW (Thorud \& Merlet, 2015). Given large shares of hydropower in the Norwegian energy system, renewable energy deployment policy measures have disfavoured PV (Hanson et al., 2011). The Norwegian PV industry thus emerged in the absence of a strong domestic market pull.

Klitkou and Godoe (2013) show that PV has received long-term public policy support, mainly via R\&D. Klitkou and Coenen (2013) find differences in regional characteristics in the Norwegian PV industry as well as knowledge spillovers from incumbent firms. It has also been shown that the PV industry has drawn on resources from the well-established silicon industry (Hanson et al., 2011). Figure 2 shows the relation between industries from which PV firms have experience from and their position in the supply chain. It illustrates that the largest share of firms indicate experience from industry and materials as important for their current PV activities. ${ }^{2}$

\footnotetext{
${ }^{2}$ This category is broader than the EIS, but captures EIS and MG-Si-TIS actors.
} 


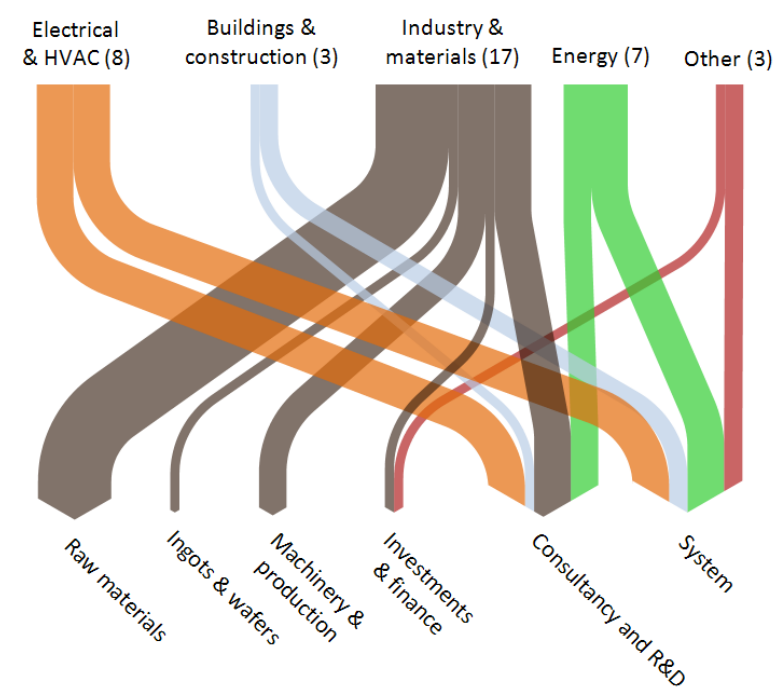

Figure 2: Experiences from other industries relevant for PV and position along PV supply chain (number of firms). Source: Normann and Hanson (2015).

While relations between established industries, such as the silicon industry and PV have been identified, the case has not been analysed with an explicit focus on how context affected the formation of the PV-TIS. The following section specifies context.

\subsubsection{Context}

The paper distinguishes between a broad sectoral context and a specific technological context that affected the formation of the PV-TIS.

The sectoral context focused upon here is the electrometallurgical industry sector (EIS) that was established in Norway. Large-scale hydropower resources provided sufficient electricity to refine, and melt a broad set of metals and alloys that became key export products (Wicken, 2011). These products include aluminium, magnesium, ferrous metals and various other materials. With particular later relevance to solar PV, Norway became the world's largest supplier of metallurgical silicon. A range of actors had production facilities in Norway, including FeSil, Finnfjord and Elkem, ${ }^{3}$ which was the world's largest silicon supplier (Ceccaroli \& Lohne, 2011).

Given how sectors tend to comprise multiple technological fields (Markard \& Truffer, 2008), the paper refers to the EIS as the sector where the technological field of metallurgical silicon processing (MG-Si-TIS) is integrated. The EIS is thus an industrial sector with the overall function of supplying products based on different types of electrometallurgical processes. Several technological fields, including silicon, are integrated with the sector to enable production and development of the processes. The EIS thus serves the function of supplying a range of electrometallurgical products, while the MG-Si-TIS refers to the actors and other structural components that are directly engaged with the generation, development and diffusion of the specific technologies enabling silicon production.

\footnotetext{
${ }^{3}$ The Søderberg electrode, which radically changed electro-chemical processing, was developed at Elkem.
} 
It is relevant to single out the MG-Si-TIS as a particular technological field in the EIS because the MG-Si-TIS has a specific relation to PV through supply chain interaction. PV technology relies on the photovoltaic effect that allows the conversion of solar radiation to electricity through semiconducting materials. The bulk share of PV manufacturing capacities are constructed for processes using high purity silicon (Ceccaroli \& Lohne, 2011). Silicon is organised in two main groups depending on material purity; ${ }^{4}$ (i) metallurgical grade silicon (MG-Si) and (ii) polysilicon or electronical grade Silicon (EG-Si). Metallurgical silicon is, for instance, used as an aluminium-silicon alloy and as an input to EG-Si used in the electronics and PV industries. Before the introduction of a dedicated silicon ${ }^{5}$ supply for PV, EG-Si was applied in the PV industry (Woditsch \& Koch, 2002). Norwegian firms in the MG-SiTIS thus traditionally supplied metallurgical silicon that was further refined to polysilicon by large multinational companies, such as Wacker and Hemlock (Enger, 2011). As illustrated in Figure 3, up-stream supply chain interaction constituted an initial link between the MG-Si-TIS and PV TIS.

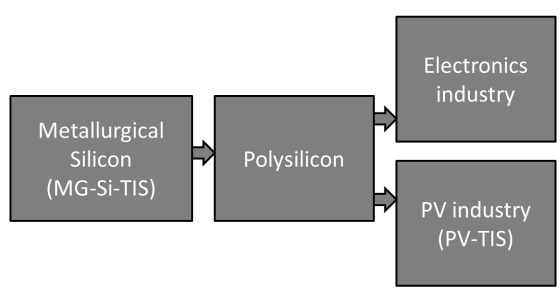

Figure 3 Supply chain relation between MG-Si-TIS and PV-TIS.

Interaction in supply chains, where one (or more) TIS supplies products or services to the focal TIS, is a common form of TIS-TIS interaction, as noted by Bergek et al. (2015). Supply chain interaction was a foundation for the more elaborate relations that that were to be established between the MG-Si-TIS and the PV TIS.

The following sections explore the development of a more elaborate relation in a historical narrative divided into two key phases identifying key events prior to and during system formation.

\subsection{Analysing the exploration phase (1980-1993)}

Firm-level and institutional pressures triggered exploration of PV as a new business opportunity for firms in the EIS. First, in terms of firm-level pressures, firms such as Elkem for instance, experienced low value added to their metallurgical silicon activities (Tronstad, 2011).

Second, broader institutional pressures emanated from uncertainties around electricity prices. In the early 1980s, a rising critique of the largely state-controlled expansion of the power sector emerged as a rising uncertainty for firms in the EIS, given their dependence on access to cheap power. Expansion of the power sector was a key part of Norway`s post-war industrialisation and elementary to the build-up of the EIS. State control of the power sector was seen as a way of subsidising the EIS, and a

\footnotetext{
${ }^{4}$ Silicon purification entails the removal of impurities, such as Boron.

${ }^{5}$ Often referred to as solar grade silicon ( $\mathrm{SoG}-\mathrm{Si}$ ) and having lower purity levels than what is required within electronics, yet sufficiently high not to compromise cell efficiency.
} 
questioning of the economic rationale for the extensive investments arose. Statkraft, ${ }^{6}$ among others, questioned whether investment in the EIS was the most socioeconomically favourable use of Norway's vast hydropower resources (Wicken, 2011). Deregulation of the power market and the introduction of a new energy law in 1991 came as a result of this debate. This contributed to increased uncertainty in electricity price development. Electricity is a key input and cost component in the EIS (NOU-9, 2012). Uncertainties arising from deregulation in the power sector raised questions about the viability of future investments and activity in the EIS due to fears of future increases in electricity prices (Wicken, 2011). Rising uncertainties thus can be seen as a form of institutional change with regards to changes in expectations for future development of the traditional activities in the EIS. The relation to the PV-TIS on the institutional level can be seen in how this uncertainty triggered exploration of new business opportunities - PV representing one such opportunity.

While the entire EIS was subject to these pressures, the interpretation of PV as a new technological opportunity was enabled by innovation along the particular trajectory of silicon refining - i.e., through specific dynamics in the MG-Si-TIS.

In terms of adaptive strategies firms pursued incremental improvements to ongoing silicon production through energy efficiency enhancements. Simultaneously firms explored opportunities to modify and develop new processes for higher silicon purity levels. The latter is linked to a large potential to increase value. For instance, upgrading MG-Si to polysilicon has been argued to multiply silicon's value by a factor of 30-50 (Ceccaroli \& Lohne, 2011). Elkem's introduction of custom purity 'Silgrain' was a step in this direction and gave particularly good results for polysilicon producers who were the main customer group. This development occurred by integration of practical know-how and scientific knowledge linked to increased understanding of material behaviour inside melting furnaces (Sogner, 2003).

Knowledge development thus evolved in the direction of higher silicon purity levels, which was of key importance for later PV-related activities (P1). Networks between industrial actors and research organisations, such as the Norwegian Institute of Technology $(\mathrm{NTH})^{7}$ and SINTEF, ${ }^{8}$ were established to pursue this goal (Tronstad, 2011).

The continuous development along the silicon trajectory opened doors to pursue PV as a specific new market segment (P4). An initial attempt in the early 1980s was Elkem's collaboration with Exxon Mobil, as well as other actors, to develop a new process to produce silicon. No formalised business plans existed and raw material specifications (purity) were unsatisfactory. The collaboration did however signal that core competencies linked to silicon were applicable for PV, which emerged as a potential future business area (P1, P4). Elkem had a tradition for acting as an R\&D partner and process developer, in part with a unique pilot plant ${ }^{9}$ that enabled largescale testing of new processes. This was an important infrastructural resource used to test various processes, including silicon for PV (P3). Through such R\&D

\footnotetext{
${ }^{6}$ Statkraft is Norway`s largest utility and fully state owned.

${ }^{7}$ NTH (Norges Tekniske Høgskole) is the predecessor of NTNU (Norges Teknisk-Naturvitenskapelige Universitet).

${ }^{8}$ The Foundation for Scientific and Industrial Research.

${ }^{9}$ Experimentation on a pilot scale was highly advantageous to explore production characteristics and their potential associated costs at a larger scale (Tronstad 2011).
} 
collaborations and export of silicon and other materials, Elkem established wide spun international networks (Tronstad, 2011).

Further exploration of the PV-TIS was pursued through strategic acquisitions. Elkem bought the British firm Crystalox in 1985, which became a leading producer of crystallisation furnaces for silicon, ${ }^{10}$ catering to the electronics industry (P1, P4) (Bjørseth, 2011).

The potential of pursuing PV silicon production was also collectively identified by several actors in the MG-Si-TIS, who had formed 'The Norwegian ferroalloy producers research association ${ }^{\prime 1}$ (FFF). While the potential was identified among the actors, it was also recognised that Norwegian firms lacked knowledge, and that Elkem, amongst others, should strengthen ties with Norwegian universities to pursue such a goal (P1, P4) (Klitkou \& Godoe, 2013). The network functioned as a broader arena for the identification of knowledge deficiencies and development paths for the MG-Si-TIS and thus impacted strongly upon key processes, such as knowledge development and the direction of search in the nascent PV-TIS (P1, P4).

The continuous innovation and development that occurred related to silicon shows support to the claim that institutionalised patterns of experimentation and innovation enhance openness and the ability to interpret and explore new technological opportunities. Exploration and interpretation of PV as a new technological opportunity was not only pursued by focal actors with relevant core competencies, but also by technology specific learning networks including other firms and universities with ties to silicon. This illustrates the fruitfulness of including the MG-Si-TIS as a technological context dimension in addition to the sectoral dimension. The MG-SiTIS as a specific technological field in the EIS could interpret the opportunities in the PV-TIS. It is thus relevant to single out this specific set of actors and networks that were engaged with developing the technological field of silicon production, with important impacts on the exploration of the PV-TIS.

\subsection{Analysing the formation phase (1994-2010)}

While exploration of PV had persisted since the early 1980s, a formative phase emerged with the start-up of the silicon wafer manufacturing firm Scanwafer in 1994 (P2). The firm was an Elkem spin-off started by Alf Bjørseth, former head of R\&D at Elkem, who had a central role in Elkem's projects working with silicon throughout the 1980s (Bjørseth, 2011; Enger, 2011). Elkem was unwilling to pursue PV further given large financial constraints and a firm strategy that was focused on core business activities (Bjørseth, 2011). Spin-off activity was a key mode of early actor entry to the PV-TIS, which enabled flows of core competencies from the MG-Si-TIS to the PVTIS (P1, P2).

While core competencies linked to silicon were important, the manufacturing of wafers also necessitated development and adaptation of manufacturing technology and skills (Bjørseth, 2011; Enger, 2011; Fernandes, 2011). An international PV

\footnotetext{
${ }^{10}$ Elkem eventually sold the company, which still exists under the name PV Crystalox and produces ingots, wafers and polysilicon for the PV industry.

${ }^{11}$ FFF (Ferrolegeringsindustriens forskningsforening) (ferro-alloy industry research association) was established in 1989 and was financed by participating firms and the Research Council of Norway.
} 
industry had emerged by the time of entry of the Norwegian actors, but there did not exist turnkey manufacturing equipment (Bjørseth, 2011). During the development of manufacturing equipment, resource flows from the related electronics industry were important (see Figure 3 for an illustration of the supply chain relation). For instance, crystallisation furnaces and wire saws were adapted for PV manufacturing from companies catering the electronics industry. ${ }^{12}$ Knowledge flows also came in disembodied forms such as consultancy. For instance, Dr David Hukin, founder of formerly Elkem-owned Crystalox, was a key member of the team planning and constructing Scanwafer's first plant (Bjørseth, 2011). Scanwafer could thus function as a gate-keeper (Graf, 2011) in mediating knowledge flows from the context. To achieve this, Scanwafer relied on networks already established in the exploration phase (P1).

Scanwafer also made use of relations to Norwegian suppliers. For instance, to expand production due to larger orders, Scanwafer collaborated with Tronrud Engineering ${ }^{13}$ to construct an automated washing and control line for silicon wafers. This had previously been done manually, and it offered an opportunity to fully automatize wafer production (P1) (Bjørseth, 2011; Fernandes, 2011). Again, networks built in the exploration phase were used. This illustrates how system elements built up in the context EIS and MG-Si-TIS, affected important functions such as knowledge development in the PV-TIS.

Scanwafer grew via expansion, establishing several manufacturing plants, and was gradually acquired by Renewable Energy Corporation (REC) (with Bjørseth's firm Scatec as the major shareholder) from 1999. This expansion triggered the entry of new firms, both wafer producers (such as Norsun) and specialised suppliers, such as silicon recycling services $(\mathrm{P} 2)$.

Much of the activity linked to PV manufacturing occurred in regions previously harbouring EIS firms and involved resource mobilisation from the EIS. Because of the increased pressures discussed in section 3.2, several EIS firms reduced activities, increased efficiency or closed down activities in Norway, often resulting in lay-offs and rises in unemployment. For instance, Hydro closed its magnesium plants in Glomfjord and Herøya and its aluminium plant in Årdal. Some of the laid-off workers were employed by Scanwafer and Norsun, respectively (Bjørseth, 2011). Changes in the EIS thus opened labour mobility to the PV-TIS from a favourable industrial culture, which included process and research competencies (P3). New industrial activities were thus sought after and supported both by firms (Hydro and Elkem), municipalities and the state (for instance, via SIVA ${ }^{14}$ and the state district and development fund $[\mathrm{SND}]^{15}$ ) (Klitkou, 2010). Some of these localities, such as Glomjord, Årdal and Herøya, offered good locations for PV activities. In particular. these locations gave access to key resources such as infrastructure and physical assets (access to cooling water and electricity) (P3). In addition, actors in the EIS contributed with the mobilisation of financial resources. For instance, Hydro invested

\footnotetext{
${ }^{12}$ This continued throughout expansion. Norsun, for instance, collaborated with the Finnish semiconductor firm Okmetic in the design of crystallisation furnaces for high efficiency monocrystalline wafers (Bjørseth 2011).

${ }^{13}$ It was a collaboration that continued with REC.

${ }^{14}$ State corporation for industry growth that amongst others develops, builds and owns infrastructure.

${ }^{15}$ Later integrated into Innovation Norway
} 
in business development firms together with municipalities (such as Meløy business development), which in turn made major investments in Scanwafer, REC and Norsun (P3) (Bjørseth, 2011). In this way, generic resource flows came from the sector.

The most significant contribution of Norwegian actors to the global PV industry was the development of a dedicated PV silicon supply. Access to silicon from polysilicon firms who also catered to the electronics industry was linked to a persistent shortage and constituted a major bottleneck for growth globally. This also lead to PV price increases for several years (Ceccaroli \& Lohne, 2011).

Norwegian firms pursued two differing technological paths to silicon production for PV purposes. First, REC as a prime mover globally, acquired and modified a polysilicon plant initially constructed by Union Carbide in Moses Lake, Washington, United States. This path involved adapting technology initially developed for the electronics industry through the development of a fluidised bed reactor that increased the efficiency of production (P1) (Enger, 2011). Second, incumbents, who at first had hesitated to enter the PV markets, developed and introduced new processes for supplying custom purity silicon for PV purposes based on modifications of metallurgical process routes (P1). Elkem was an early mover globally to establish production of this silicon type in 2009 (Tronstad, 2011). In this way, core competencies developed in the Mg-Si-TIS were used to start silicon production for PV purposes (P1, P2). Early experimentation with a variety of process configurations from the 1980s onwards was important for the initial production in Elkem Solar. This experimentation allowed for knowledge accumulation in terms of which types of processes routes that would be technologically and economically feasible. Access to testing infrastructure and pilot production was critical as it allowed the verification of processes and reduced costs in large-scale industrial production (P1, P3) (Tronstad, 2011). While Elkem previously had contributed to important resource flows, it now engaged with the PV-TIS through diversification as a mode of actor entry (P2). Fesil, Hydro and several smaller start-ups followed suit by attempting to develop and industrialise new silicon processes. Elkem Solar so far ended up being the only firm pursuing large-scale silicon manufacturing on Norwegian soil.

Figure 4 illustrates actors and events over time. Figure 4 does not cover all actors in the TIS but rather highlights some key actors and events and illustrates lineages from early experimentation in the MG-Si-TIS to the evolving activities in the PV TIS. As illustrated, the early phase exploration of PV occurred in the MG-Si-TIS, with subsequent resource flows from the broader EIS. PV specific activities emerged in the mid-1990s through Scanwafer and later through entry of other firms. Institutional change and relevant policy measures are included in a separate box, due to how these target broader technologies and sectors than the PV-TIS, MG-Si-TIS and EIS. . R\&D actors played an important role in system formation, but are not included as they generally have numerous and differing ties with a multitude of actors over time (Klitkou \& Coenen, 2013). For the same reason, the funding of public R\&D support is only indicated for the PV-TIS or MG-Si-TIS and not for individual actors.

Universities and research institutes increased focus on solar PV projects and infrastructural development directly linked to PV with support from the Norwegian Research Council (NRC), amongst others (Hundere, 2011; Ibenholt, 2011). For instance, the NTNU-led initiative 'from sand to solar cells' indicated a direction for 
research on PV silicon (P4) (Klitkou \& Godoe, 2013). In addition, the Institute for Energy Technology (IFE) constructed a cell production line for R\&D purposes, which enabled close cooperation with several Norwegian companies (P1, P3) (Marstein, 2011). Klitkou and Godoe (2013) show how public R\&D support was mobilised for PV-related activities from the 1980s and onwards through NRC programmes targeted towards the EIS (such as EXPOMAT ${ }^{16}$ and PROSMAT ${ }^{17}$ ). The authors estimate there were 90 NRC funded projects focusing on PV in the period 1996-2009, often involving firm participation or leadership with links to the MG-Si-TIS (P1, P3). The emergence of so-called centres for environmentally friendly energy research, supported by the NRC, also contributed to the development of formalised networks focused on PV (P1, P3).

${ }^{16}$ R\&D for export-oriented material production and improvement.

${ }^{17}$ Process and material technology. 


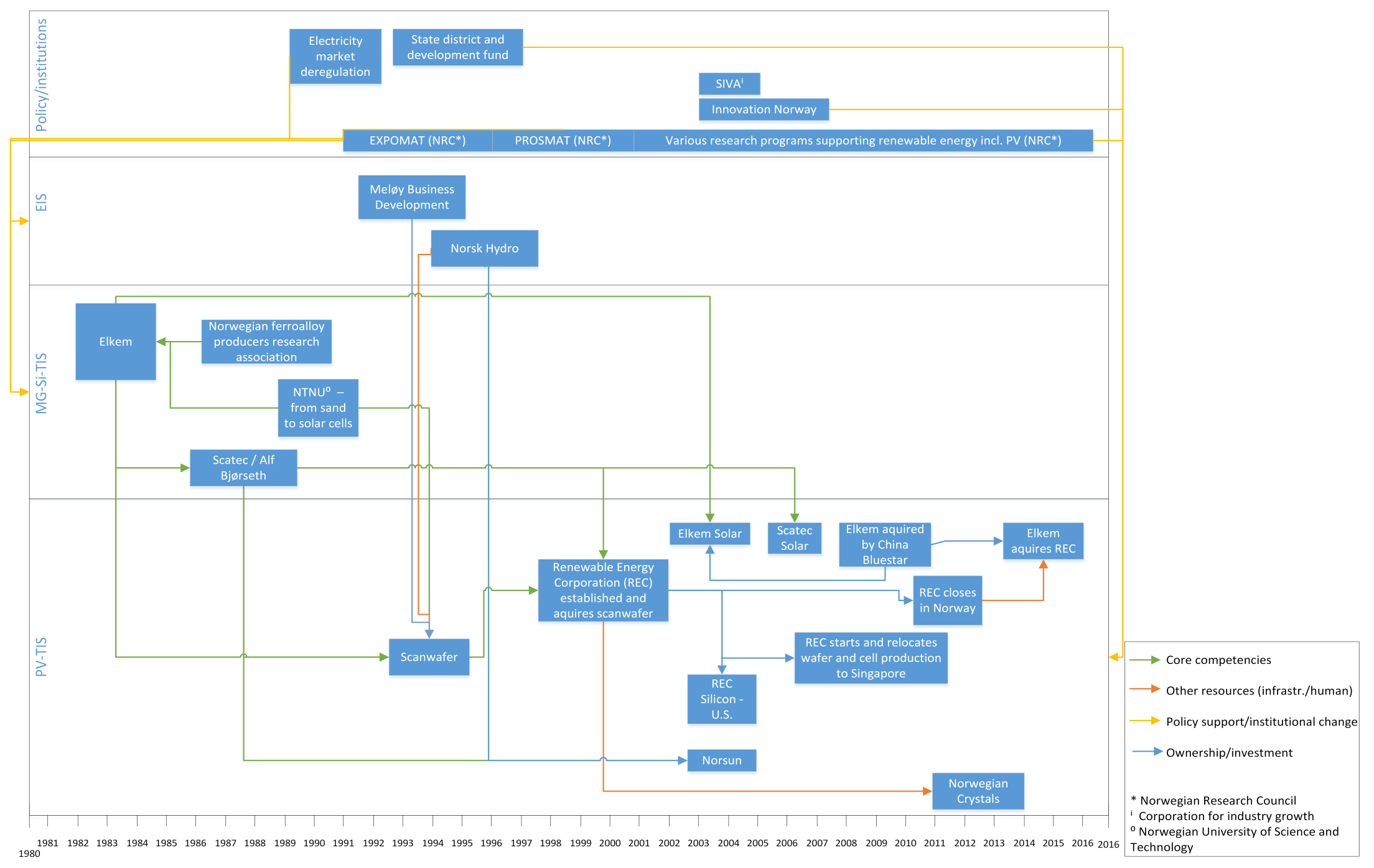

Figure 4: Lineage of central developments in the Norwegian PV industry 1980-2016. 


\subsection{Struggles with reaching a growth phase}

A note needs to be made with regards to the temporal scope in the previous sections, which focus on a period from the early 1980s until 2010. From 2011 and a few years onwards, as was the case with PV industries in several other countries, several Norwegian firms (notably REC and several of its local suppliers) relocated or closed down production. This broader TIS dynamic may in part be attributed to China's rapid rise in the PV industry, increased competition and subsequent rapid price drop. As the PV industry in Norway mainly attained legitimacy as an industrial venture, and less as a technology to solve domestic problems like emission reduction or energy security, developments in the international PV-TIS may also have challenged the maintenance of legitimacy (-P6).

Actors have pursued different strategies to deal with increasing competition. Some firms have focused on competing on quality, for instance through high-efficiency wafers in Norsun (Nielsen, 2011). Others have pursued internationalisation strategies (REC's activities in Singapore) in part due to a perceived better availability of human resources (Enger, 2011). Another strategy for several firms in the raw material supply segment has been to further focus on developing PV silicon processes with low emissions and energy consumption. This segment is, however, highly capital intensive (Ceccaroli \& Lohne, 2011). Normann and Hanson (2015) observe that a significant proportion of PV firms report access to financial capital as a key barrier (-P3). While the MG-Si-TIS and the broader EIS impacted resource mobilisation in the formative phase, the reported lack of access to financial capital may be one of the barriers for reaching a growth phase. This supports the argument by Karltorp (2014) that access to sufficient resources represents a key barrier for TISs to transition into a growth phase.

Further explanations linked to struggles with reaching a growth phase may be linked to weak domestic market formation (-P5). From the start of TIS formation, ties to the international PV-TIS were vital as Norwegian actors relied on market formation processes in countries such as Japan and later Germany. Normann and Hanson (2015) however find that $70 \%$ of Norwegian PV firms find it challenging to find customers and experience uncertainties with regards to demand. Nationally, similar to the much larger German market, the downstream segment was not able to sustain the upstream segment. Upstream and downstream segments of the supply chain segments thus can be seen as relatively detached given that the downstream segment is dependent on its relation to the energy sector, which thus differs from the EIS.

Many firms, both upstream and downstream, thus target international markets. After overcoming a challenging period from 2011 key actors in the industry maintain production and activities in Norway. Elkem Solar for instance used the challenging period to improve production processes and is in full production as of 2014 (Qvale, 2014). In 2016 Elkem Solar took over RECs plant in Herøya to start silicon ingot production. Norsun, Norwegian Crystals as well as R\&D actors have also maintained their activities. In the downstream segment, Scatec Solar has grown by projecting and developing a range of large solar parks in South Africa and other countries (Slengesol, 2017). At the same time the growth in the domestic market since 2014 has been supported by the entry of several new firms, with new business models, in the system integration segment. Finally, the PV firms surveyed in Normann and Hanson (2015) express positive future expecations in terms of increase in production and 
revenue. Together this signals a persistence among actors in several segments of the PV-TIS to maintain PV activities and efforts to reach a growth phase.

\section{Discussion}

In terms of TIS context relations, the phases analysed in Sections 3.2 and 3.3 illustrate shifts over time with regards to the extent of overlaps between TIS and context, and which types of resource flows occur. First, vertical supply chain interaction (i.e., MGSi exports) existed prior to the exploration phase, and it can be seen as a starting point for the activities in the subsequent phases.

Second, the exploration phase is characterised by profound overlaps between the PVTIS and context, as illustrated in Figure 5. In structural terms, overlap on the actor level can be seen in how firms pursued both established activities while exploring PV as a means of pursuing vertical forward integration. On the network level, overlaps can be identified in how the FFF as a set of actors initially engaged with ferroalloys and silicon expanded the borders to include PV as a technological field. In addition, networks, both nationally and internationally, between actors in the MG-Si-TIS as well as to polysilicon and electronics were key to the firms' exploration activities. In this phase, we also see how institutional change in the EIS and MG-Si-TIS (increased uncertainty due to electricity market deregulation), influenced search activities that spurred new TIS formation. In the exploration phase, PV-TIS elements were nested in the MG-Si-TIS, illustrating a high degree of sharing of elements.

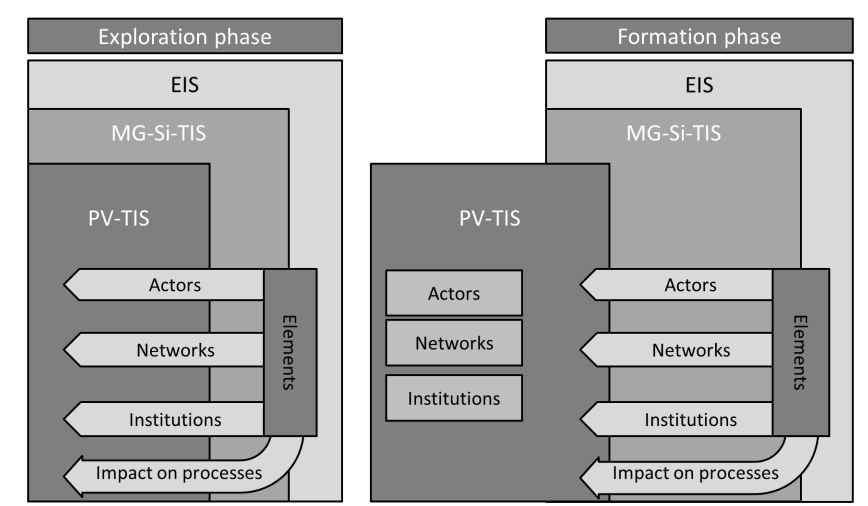

Figure 5: TIS context relations in exploration and formation phase.

Third, we see a formation phase where focal TIS structures emerge and materialise beyond the dimension of overlap, as illustrated in Figure 5. Spin-off activity and the entry of specialised actors, such as Scanwafer and later REC, indicate that the first PV activities occurred with more distance and less dependence and overlap with context than in the exploration phase. PV-focused networks similarly indicate a higher degree of independence. Ties to the MG-Si-TIS and the EIS, however, remained in terms of actor overlaps (such as Elkem), the use of networks established in the exploration phase, and the flow of human and financial capital. The formation phase is thus characterised by the development of PV-TIS specific structures, partial remaining overlaps, and persistent resource flows from both the MG-Si-TIS and the EIS. In summary, the analysis of different phases of development shows that the extent of which a TIS is nested in context can change over time. This ranges from the PV-TIS 
being fully integrated, to the development of TIS specific structures that depend less on context.

The analysis illustrates the fruitfulness of distinguishing between a sectoral and technological context. Although these contexts overlap, the analysis shows that the particular technological field of MG-Si enabled the relation to the PV-TIS due to the supply chain relation between them. The presence of the MG-Si-TIS already integrated with the EIS enabled the exploration of the particular technological field of $\mathrm{PV}$ as a new opportunity where core competencies of the MG-Si-TIS could be applied.

The analysis supports the claim made by Dolata (2009) that sectors with institutionalised patterns of innovation have better opportunities to interpret, engage with and thus also provide beneficial resources to emerging technologies. Specifically, the observed continuous innovation in the MG-Si-TIS enabled early connections to the PV-TIS. Moreover, the differentiation between the sectoral and specific technological context segments provides additional explanatory power as to how relations to the emerging technology were formed from the perspective of the sector.

The two contexts impacted the PV-TIS differently with regards to the key processes that underlie industry formation, as illustrated in Figure 6. The MG-Si-TIS impacted a broad range of processes, while the EIS mainly impacted resource mobilisation. Given the profound sharing of elements between the PV-TIS and MG-Si-TIS, both at the actor and network level, it is not surprising that this particular segment of the sector impacted the PV-TIS strongly across many functions. Knowledge development is a key process that was impacted early on through the efforts to develop processes for production of higher silicon purity. Knowledge development in turn impacted upon the direction of search towards the PV-TIS, given that it was shown feasible to use and develop existing competencies for application in the PV-TIS. During formation, structures in the MG-Si-TIS also impacted on entrepreneurial experimentation through spin-offs and diversification as well as the use of existing networks to facilitate resource mobilisation.

The resource flows from the two contexts differ. While technology-specific core competencies linked to silicon production and materials were transferred through spin-offs and diversification from the MG-Si-TIS, the EIS contributed with more generic resources such as finance, labour and infrastructures. 


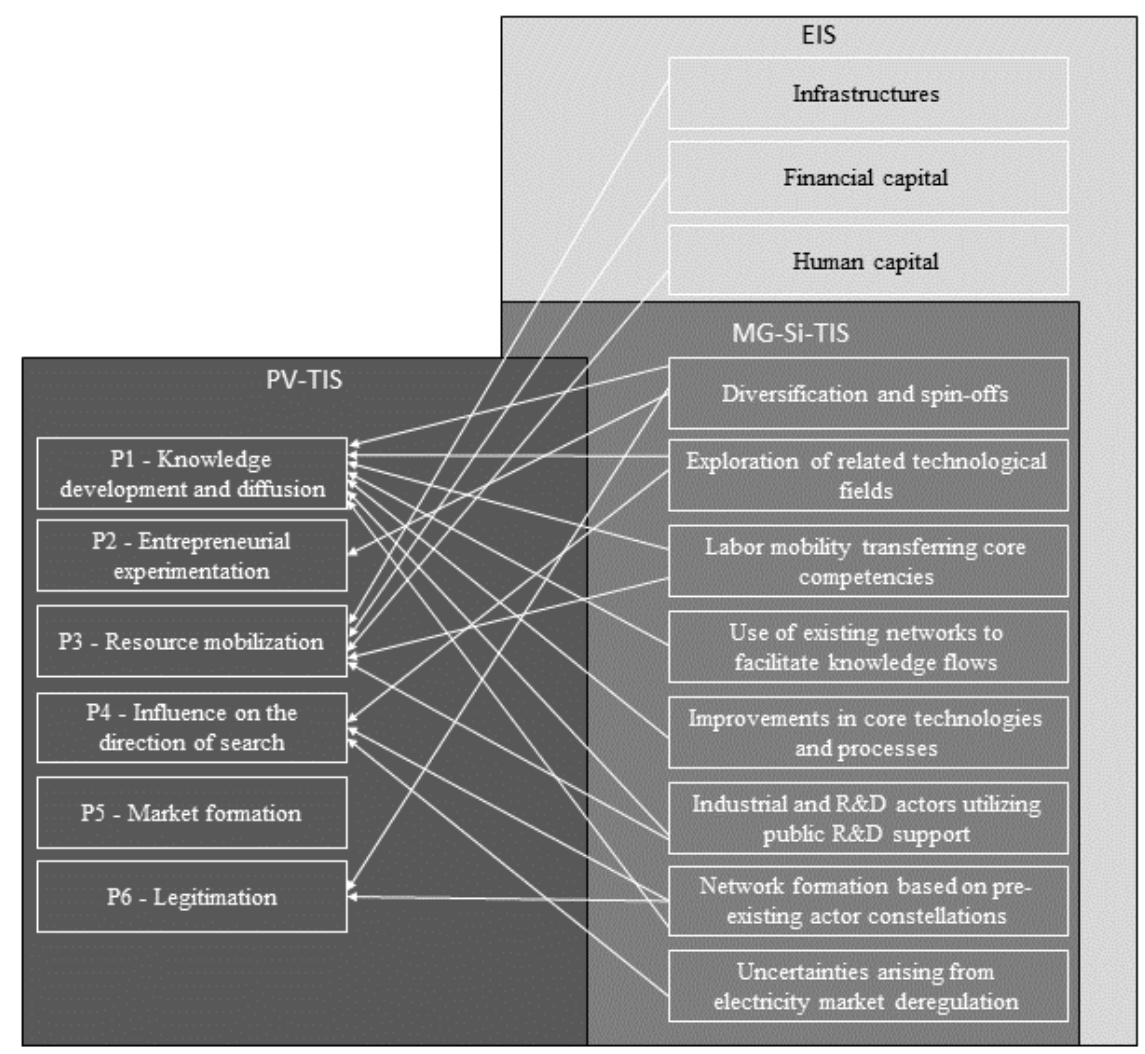

Figure 6: Influence from MG-Si-TIS and EIS on PV-TIS processes.

\section{Conclusions}

The purpose of this paper was to explore if emerging industries can benefit from the resources embedded in established industries. Specifically, the paper set out to explore under which conditions established industries can contribute to new TIS formation. Drawing on the TIS perspective, the paper outlined a framework that focused on relations between a focal, a context TIS and a broader sector. The framework was applied to analyse the formation of a PV-TIS in Norway and how its relations to the MG-Si-TIS and EIS evolved over time, both prior to and during the processes of system formation.

The paper contributes to the TIS literature in several ways. First, it shows how contextual sectors and TIS can provide a structural foundation for formation of a focal TIS. The paper observed this to take place through sharing of elements in terms of firms pursuing exploration, actor entry (both diversifiers and spin-offs), and reliance on pre-existing networks. Such a mode of system formation is here seen to involve specific parts of the EIS (the technologically related MG-Si-TIS) enabling a connection to the PV-TIS via overlap of the elements. This confirms, as suggested by Bergek, Jacobsson, and Sandén (2008), that TISs at early stages of development only have a few structures in place, but instead draw on established structures and resources.

Second, and adding to the assertions on overlaps made by Bergek Bergek, Jacobsson, and Sandén (2008), the paper illustrates how the relationship between TIS and context changes over time. Supply chain interaction between the MG-SI-TIS and PV served 
as a foundation for exploration activities and attempts at vertical forward integration. The MG-SI-TIS and PV-TIS at first enjoyed a profound overlap in the exploration phase. In the formation phase the PV-TIS started developing system-specific structures, such as dedicated actors and networks. Yet, the PV-TIS continued to draw on resource flows from the MG-SI-TIS the broader EIS in the formation phase. The analysis shows that the development of technology-specific system elements, such as specialised firms or networks, emerged based in part on the structural foundations presented by the context. This occurred after a period with a large degree of sharing of the elements. The extent of technology-specific and shared system elements present in a TIS thus can vary over time as it matures.

The analysis in this paper mainly focused on the formative phase. The observed struggles with moving into a growth phase indicate there may be limits to maintaining the positive impact of established industries over time. In part this may be due to how certain processes in the TIS, such as market formation, legitimacy creation and entrepreneurial experimentation, evolve independently from the contexts studied in this paper. In terms of policy, stronger development of these processes could thus benefit from technology-specific measures or the development of stronger ties to other countries where these are better developed to facilitate resource mobilisation and market access. One limitation of this study is that it does not analyse the relations to other nationally delineated TISs. This would require a different frame of analysis. For instance, the framework proposed by Binz, Truffer, and Coenen (2014), suggests analysing nationally delimited sub-TISs that are linked internationally.

Third, in addition to overlaps, the paper used the notion of flows to describe impact from context to TIS. The analysis showed flows to be a useful category to capture the one-directional influence between context and TIS, such as the transfer of key resources from the context to the TIS. These flows impacted key processes in the PVTIS during formation, such as knowledge development, resource mobilisation and direction of search. The notion of flows is thus a useful addition to the conceptual apparatus characterising TIS-context relations and distinguishable from categories, referring to a more two-directional impact (such as structural couplings) (Bergek et al., 2015).

Fourth, distinguishing analytically between technological and sectoral contexts allowed the identification of different types of flows. The MG-Si-TIS provided flows of core competencies, in particular, while the broader sector provided more generic, but also important, resources, such as infrastructures and labour mobility. Moreover, the differentiation between technological and sectoral contexts allowed a better identification of the particular technological segment of the EIS that enabled a relation to materialise with the PV-TIS. The technologically-related MG-Si-TIS embedded in the sector thus played a key role in allowing actors to interpret, engage and link up with the PV-TIS. The framework developed in this paper thus offers additional explanatory power with regards to how sectors may engage with, and thus impact emerging technological opportunities in a beneficial way. Further research could inquire how engagement with novel technological fields that offer such opportunities can be maintained over time, and materialise beyond a formative phase, and potentially develop into stronger structural couplings. 
Thus, while it has been beyond the scope of this paper to analyse how and to what extent developments in the focal TIS have impacted the context, this could be explored more in future research. Relevant issues include how and when structural couplings are developed (when a one-directional flow relation already exists), or to what extent knowledge bases in the context are enhanced through activities in the focal TIS.

The potential for established industries as foundations for new industry emergence also has implications for policy. The findings illustrate there is potential for stimulating resource transfer and sharing of elements between established and emerging industries. This could be strengthened by incentives for exploration and development of national and international networks that increase opportunities for interpretation of opportunities in emerging technological fields. A cautionary approach is however warranted given that the findings in this paper suggest that there may be limits to maintaining a positive contribution from the established industry over time. A specific focus on the dynamics pertaining to the new industry in combination with an assessment of context is therefore necessary.

\section{Acknowledgements}

I wish to thank the editor and two anonymous reviewers for helpful comments. I'm also grateful to Håkon Normann (TIK) for comments on an earlier version of the paper. In addition, thanks to Allan Dahl Andersen (TIK) for lengthy discussions on the relations between old and new industries and various notions of TIS context. I gratefully acknowledge funding from the Norwegian Research Council, grant number 209697/E20. 


\section{References}

Acs, Z. J., Audretsch, D. B., \& Feldman, M. P. (1994). R \& D Spillovers and Recipient Firm Size. The Review of Economics and Statistics, 76(2), 336-340. doi: $10.2307 / 2109888$

Bergek, A., Hekkert, M., Jacobsson, S., Markard, J., Sandén, B., \& Truffer, B. (2015). Technological innovation systems in contexts: Conceptualizing contextual structures and interaction dynamics. Environmental Innovation and Societal Transitions, 16, 51-64. doi:http://dx.doi.org/10.1016/j.eist.2015.07.003

Bergek, A., Jacobsson, S., Carlsson, B., Lindmark, S., \& Rickne, A. (2008). Analyzing the functional dynamics of technological innovation systems: A scheme of analysis. Research policy, 37(3), 407-429. doi:http://dx.doi.org/10.1016/j.respol.2007.12.003

Bergek, A., Jacobsson, S., \& Sandén, B. A. (2008). 'Legitimation' and 'development of positive externalities': two key processes in the formation phase of technological innovation systems. Technology analysis \& strategic management, 20(5), 575-592. doi:10.1080/09537320802292768

Berggren, C., Magnusson, T., \& Sushandoyo, D. (2015). Transition pathways revisited: Established firms as multi-level actors in the heavy vehicle industry. Research policy, 44(5), 1017-1028. doi:http://dx.doi.org/10.1016/j.respol.2014.11.009

Binz, C., Truffer, B., \& Coenen, L. (2014). Why space matters in technological innovation systems-Mapping global knowledge dynamics of membrane bioreactor technology. Research policy, 43(1), 138-155.

Bjørseth, A. (2011, 23.11.2011 \& 5.12.2011) Interview with Alf Bjørseth, CEO and chairman of the board, Scatec.

Breschi, S., Lissoni, F., \& Malerba, F. (2003). Knowledge-relatedness in firm technological diversification. Research policy, 32(1), 69-87. doi:http://dx.doi.org/10.1016/S0048-7333(02)00004-5

Ceccaroli, B., \& Lohne, O. (2011). Solar Grade Silicon Feedstock Handbook of Photovoltaic Science and Engineering (pp. 169-217): John Wiley \& Sons, Ltd.

Cohen, W. M., \& Levinthal, D. A. (1990). Absorptive Capacity: A New Perspective on Learning and Innovation. Administrative Science Quarterly, 35(1), 128152. doi: $10.2307 / 2393553$

Dolata, U. (2009). Technological innovations and sectoral change: Transformative capacity, adaptability, patterns of change: An analytical framework. Research policy, 38(6), 1066-1076. doi:10.1016/j.respol.2009.03.006

Enger, O. (2011, 12.12.2011) Interview with Ole Enger, CEO, REC.

Erlinghagen, S., \& Markard, J. (2012). Smart grids and the transformation of the electricity sector: ICT firms as potential catalysts for sectoral change. Energy Policy, 51, 895-906. doi:10.1016/j.enpol.2012.09.045

Feldman, M. P. (1994). Knowledge Complementarity and Innovation. Small Business Economics, 6(5), 363-372.

Fernandes, T. (2011, 24.10.2011) Interview with Tommy Fernandes, consultant, Tronrud Engineering.

Forbes, D. P., \& Kirsch, D. A. (2011). The study of emerging industries: Recognizing and responding to some central problems. Journal of Business Venturing, 26(5), 589-602. doi:http://dx.doi.org/10.1016/j.jbusvent.2010.01.004

Frenken, K., \& Boschma, R. A. (2007). A theoretical framework for evolutionary economic geography: industrial dynamics and urban growth as a branching process. Journal of Economic Geography. doi:10.1093/jeg/lbm018 
Garud, R., \& Karnøe, P. (2001). Path dependence and creation. Mahwah, N.J.: Lawrence Erlbaum Associates.

Geels, F. W. (2002). Technological transitions as evolutionary reconfiguration processes: A multi-level perspective and a case-study. Research policy, 31(89), 1257-1274.

Geels, F. W., Kern, F., Fuchs, G., Hinderer, N., Kungl, G., Mylan, J., . . . Wassermann, S. (2016). The enactment of socio-technical transition pathways: A reformulated typology and a comparative multi-level analysis of the German and UK low-carbon electricity transitions (1990-2014). Research policy, 45(4), 896-913. doi:http://dx.doi.org/10.1016/j.respol.2016.01.015

Graf, H. (2011). Gatekeepers in regional networks of innovators. Cambridge Journal of Economics, 35(1), 173-198. doi:10.1093/cje/beq001

Hanson, J., Kasa, S., \& Wicken, O. (2011). Energirikdommens paradokser Innovasjon som klimapolitikk og noeringsutvikling. Oslo: : Universitetsforlaget.

Hekkert, M. P., Suurs, R. A. A., Negro, S. O., Kuhlmann, S., \& Smits, R. E. H. M. (2007). Functions of innovation systems: A new approach for analysing technological change. Technological Forecasting and Social Change, 74(4), 413-432.

Hundere, A. M. (2011, 28.10.2011) Interview with Aase Marie Hundere, senior advisor, Norwegian Research Council.

Ibenholt, T. (2011, 28.10.2011) Interview with Tone Ibenholt, special advisor, Norwegian Research Council.

Jacobsson, S. (2008). The emergence and troubled growth of a 'biopower' innovation system in Sweden. Energy Policy, 36(4), 1491-1508. doi:http://dx.doi.org/10.1016/j.enpol.2007.12.013

Karltorp, K. (2014). Scaling up renewable energy technologies. The role of resource mobilisation in the growth of technological innovation systems. (PhD), Chalmers Universty of Technology, Gothenburg.

Klepper, S. (2002). The capabilities of new firms and the evolution of the US automobile industry. Industrial and Corporate Change, 11(4), 645-666. doi:10.1093/icc/11.4.645

Klitkou, A. (2010). Kompetansebehov i grønn jobber: En casestudie fra solcelleindustrien. Retrieved from Oslo:

Klitkou, A., \& Coenen, L. (2013). The Emergence of the Norwegian Solar Photovoltaic Industry in a Regional Perspective. European Planning Studies, 21(11), 1796-1819.

Klitkou, A., \& Godoe, H. (2013). The Norwegian PV manufacturing industry in a Triple Helix perspective. Energy Policy, 61, 1586-1594. doi:http://dx.doi.org/10.1016/j.enpol.2013.06.032

Krafft, J., Lechevalier, S., Quatraro, F., \& Storz, C. (2014). Emergence and evolution of new industries: The path-dependent dynamics of knowledge creation. An introduction to the special section. Research policy, 43(10), 1663-1665. doi:http://dx.doi.org/10.1016/j.respol.2014.07.006

Markard, J. (2016). Conceptualizing the life cycle of technological innovation systems. Paper presented at the 7th International Sustainability Transitions Conference, Wuppertal.

Markard, J., Hekkert, M., \& Jacobsson, S. (2015). The technological innovation systems framework: Response to six criticisms. Environmental Innovation and Societal Transitions, 16, 76-86. doi:http://doi.org/10.1016/j.eist.2015.07.006 
Markard, J., Raven, R., \& Truffer, B. (2012). Sustainability transitions: An emerging field of research and its prospects. Research policy, 41(6), 955-967. doi:http://dx.doi.org/10.1016/j.respol.2012.02.013

Markard, J., \& Truffer, B. (2008). Technological innovation systems and the multilevel perspective: Towards an integrated framework. Research policy, 37(4), 596-615. doi:http://dx.doi.org/10.1016/j.respol.2008.01.004

Markides, C. C., \& Williamson, P. J. (1994). Related Diversification, Core Competencies and Corporate Performance. Strategic Management Journal, $15,149-165$.

Marstein, E. S. (2011, 7.11.2011) Interview with Erik Stensrud Marstein, principal scientist, institute for energy technology (IFE.

Musiolik, J. (2012). Innovation system-building: on the role of actors, networks and resources. The case of stationary fuel cells in Germany. (PhD), Utrecht University.

Neffke, F., Henning, M., \& Boschma, R. (2011). How Do Regions Diversify over Time? Industry Relatedness and the Development of New Growth Paths in Regions. Economic Geography, 87(3), 237-265. doi:10.1111/j.19448287.2011.01121.x

Nielsen, Ø. (2011, 5.12.2011) Interview with Øyvind Nielsen, Vice President R\&D, Norsun.

Normann, H. E., \& Hanson, J. (2015). Exploiting global renewable energy growth: Opportunities and challenges for internationalisation in the Norwegian offshore wind and solar energy industries. Retrieved from Trondheim:

NOU-9. (2012). Energiutredningen - verdiskaping, forsyningssikkerhet og miljø. Norges Offentlige Utredninger.

Qvale, P. (2014, 28.01.2014 ). Elkem Solar starter full produksjon. Teknisk Ukeblad.

Sandén, B., \& Hillman, K. (2011). A framework for analysis of multi-mode interaction among technologies with examples from the history of alternative transport fuels in Sweden. Research policy, 40(3), 403-414.

Slengesol, I. (2017, 11.04.2017). Solenergi er en vinnerteknologi. Sysla Grønn.

Smith, A., Stirling, A., \& Berkhout, F. (2005). The governance of sustainable sociotechnical transitions. Research policy, 34(10), 1491-1510. doi:10.1016/j.respol.2005.07.005

Smith, K. (2002). What is the 'knowledge economy'? Knowledge intensive industries and distributed knowledge bases. Maastricht, Netherlands: United Nations University.

Sogner, K. (2003). Skaperkraft: Elkem gjennom 100 år 1904-2004. Oslo: Messel Forlag.

Thorud, B., \& Merlet, S. (2015). Solenergi i Norge: Status og framtidsutsikter. Retrieved from http://energiogklima.no/kommentar/solenergi-i-norge-statusog-framtidsutsikter/

Tronstad, R. (2011, 14.12.2011) Interview with Director R\&D, Elkem Technology.

Wicken, O. (2011). Kraft fra infrastruktur til marked. In J. Hanson, S. Kasa, \& O. Wicken (Eds.), Energirikdommens paradokser - Innovasjon som klimapolitikk og noeringsutvikling. Oslo: Universitetsforlaget.

Wirth, S., \& Markard, J. (2011). Context matters: How existing sectors and competing technologies affect the prospects of the Swiss Bio-SNG innovation system. Technological forecasting \& social change, 78(4), 635-649.

Woditsch, P., \& Koch, W. (2002). Solar grade silicon feedstock supply for PV industry. Solar Energy Materials \& Solar Cells, 72, 11-26. 
